\title{
The integrated reporting: A presentation of the current state of art and aspects of integrated reporting that need further development
}

\author{
Jordi Morros \\ Universitat de Barcelona (Spain) \\ jmorros@ub.edu
}

Received July, 2015

Accepted January, 2016

\section{Abstract}

Purpose: The purpose of this paper is to synthesize what is the emerging field of integrated reporting, with particular emphasis in the International Integrated Reporting Council, and outline a list of items for future research in this area.

Design/methodology/approach: The approach is to outline a presentation of integrated reporting (IR), and make a review of the implications for the research agenda of the most important items.

Findings: The need for quality researchers to address a number of pressing challenges posed by the rapid development of IR policies and practices.

Research limitations/implications: The paper provide insights into issues and aspects of integrated reporting that need further development and need robust evidence to help inform improvements in policy and practice.

Practical implications: Highlight how companies may benefit from integrated reporting in response to stakeholders' calls for enhanced disclosure of environmental, social, governance and other non financial information.

Social implications: The main social implication is to promote the wider public interest of improving the relevance of information for decision-making, for all stakeholders, and allow greater efficiency in the allocation of financial and other resources and in adding public value. 
Originality/value: This paper offers a general view on a subject that is a challenge for entities oriented to the implementation of sustainability in their values and also in their reporting.

Keywords: Integrated reporting, IIRC \& Sustainability reporting

Jel Codes: M14, M41

\section{Introduction}

Integrated reporting (IR) is the logical consequence of the growth of sustainability and corporate responsibility as issues, both as such and in reporting. About 300 responsibility reports were published in the mid-90s; about 3,000 were produced in 2010. This number has probably trebled in less than five years, with a growing tendency towards combined and integrated reporting. One report out of three in the 2014 Annual Report on Annual Reports top 50 may qualify, partly or fully, as "integrated".

Companies must now report to a broader audience than shareholders -themselves often looking beyond numbers too- and speak to several categories of stakeholders. These expect more than accounts, financials and business indicators, and want to know why, where and how companies create and add value, and how they deal with responsibility and sustainability.

Initially the IR took place predominantly through disclosures within corporate annual (financial) reports. Over the past two decades, however, social and environmental disclosures have increasingly been made in separate stand-alone reports in addition to a variety of other media such as web sites. These stand-alone social and environmental reports have become more complex (and long) as a greater range of issues has been disclosed to meet the supposed information needs of a range of stakeholders.

IR has rapidly gained considerable prominence since the formation in 2010 of the International Integrated Reporting Committee (IIRC - subsequently renamed the International Integrated Reporting Council). Although the IIRC has become the dominant body globally in developing policy and practice around IR, it was not the first mover in this area. The concept of integrated reporting has been undertaken by two separate bodies, the King Report on Governance for South Africa (King III) (Integrated Reporting Council of South Africa (IRCSA, 2011)), and the International Integrated Reporting Council in the UK (IIRC, 2013a). Preparing an integrated report became mandatory starting 1 March 2010 for organizations listed on the Johannesburg Stock Exchange. Elsewhere in the world, several organizations are trialling preparations of an integrated report with the concept, process, and reporting still evolving, and with no unified description of this concept (Cheng, Green, Conradie, Konishi \& Romi, 2014). 
The two institutions have not, however, articulated what is meant by coherent whole and how the connectivity between different reporting strands should be unified. I therefore note that integrated reporting makes the organization accountable about its performance to stakeholders in reaching its vision (long-term) through the use of multi-dimensional (financial, non-financial, social, and environmental) resources.

IR brings governance, financial capital, intellectual capital, social capital, and environmental capital onto a common platform. The diverse dimensions of organisational performance are unified under the organisational vision and organization's values. A responsible organization can state its vision (what it wants to become) for a future point in time that pre-empts its directional mission, and can state the values (the underpinning moral consciousness) upon which it formulates mission - the purpose for which the organization exists. Based on an organisational vision and values, an integrated report combines diverse dimensions of organisational performance, to demonstrate how an organization's vision and values are internalized within and externalised outside the organization. The organisational context in which it conducts its operations helps to determine and pre-empt the internal and external risk profile.

The aim of this paper is to begin to meet this need by tracing the early development and current state-of-play of IR and setting out some points that can be included in the agenda for future research.

\section{Origins and evolution of the IIRC}

In 2004, the Prince's Accounting for Sustainability Project (A4S) was formed, and A4S developed a reporting framework in 2007 and a reporting "how to" guide in 2009, which explain how all areas of organizational performance can be presented in a connected, integrated way, reflecting the organization's strategy and the way it is managed.

Following the success of the work undertaken by A4S and others, at the A4S Forum event on 17th December 2009 His Royal Highness The Prince of Wales, on behalf of A4S, the Global Reporting Initiative (GRI) and International Federation of Accountants (IFAC), called for an "International Integrated Reporting Council" (IIRC) to be established to oversee the development of an international connected and integrated approach to corporate reporting. A4S works to promote the Integrated Thinking that is required if organizations are to achieve successful IR. Only once organizations are thinking in an integrated way, can this be demonstrated through IR.

Integrative Thinking is the ability to constructively face the tensions of opposing models, and instead of choosing one at the expense of the other, generating a creative resolution of the 
tension in the form of a new model that contains elements of the both models, but is superior to each. The Rotman School from the University of Toronto is a business school that focuses on understanding and analyzing how people use mental models in their everyday lives and in the management of business, but it is not addressed specifically to the reporting of organizations.

The IIRC was set up in 2010 comprising an international cross section of leaders from the corporate, investment, accounting, securities, regulatory, academic and standard-setting sectors as well as civil society.

According to the A4S web-site, the IIRC's foundation is to be traced to a speech made by the Prince of Wales in December 2009 in which he called for the establishment of this body. In his speech, he mentioned the GRI and, when the IIRC was formally set up in August 2010, A4S and the GRI issued a joint press release, which set out the rationale for the creation of the IIRC in the following terms:

"The world has never faced greater challenges: over-consumption of finite natural resources, climate change, and the need to provide clean water, food and a better standard of living for a growing global population. Decisions taken in tackling these issues need to be based on clear and comprehensive information; but, as the Prince of Wales has said, we are at present "battling to meet 21st century challenges with, at best, 20th century decision making and reporting systems".

The IIRC's remit is to create a globally accepted framework for accounting for sustainability... The intention is to help with the development of more comprehensive and comprehensible information about an organization's total performance, prospective as well as retrospective, to meet the needs of the emerging, more sustainable, global economic model" model" (See Press Release "Formation of the International Integrated Accounting Committee" available of the IIRC's web-site at http://www.theiirc.org/wpcontent/uploads/2011/03/Press-Release1.pdf)

This press release bears explicit signs of the Prince's idealism: accounting is to be given the task of saving the planet (or at least to try it!).

The IIRC's business case framing leads to a conception of social and environmental reporting that is even narrower than the GRI in terms of inputs and that grossly oversimplifies the challenges of sustainability. For example, the IIRC and organizations participating in their pilot program highlight issues such as business strategy, governance, performance and prospects, with minimal acknowledgment of divergent socio-political understandings of sustainability and their implications for assessing issues of "value" and "materiality".

In November 2011, the IIRC announced a number of changes to its organisational structure. Under the new arrangements, an initial transitional phase until the end of 2013 will see the 
IIRC supported by a strengthened secretariat operating through a not-for-profit company established for the purpose under the same name.

The mission of the IIRC is to create a globally accepted IR framework which brings together financial, environmental, social and governance information in a clear, concise, consistent and comparable format.

The company's board will comprise Mervyn King as Chairman, Leslie Ferrar (Treasurer, Household of the Prince of Wales and the Duchess of Cornwall) and Christy Wood (Chairman of the Board of Governors, International Corporate Governance Network) as Deputy Chairs, together with Ian Ball (Chief Executive, International Federation of Accountants), Ernst Ligteringen (Chief Executive, Global Reporting Initiative till July 2014), Jessica Fries (Director, The Prince's Accounting for Sustainability Project) and the IIRC's Chief Executive, Paul Druckman. A Governance Committee has also been established, with responsibilities relating to audit, nominations and executive remuneration for the company.

The IIRC's most remarkable feature at its incorporation was the extraordinarily high-powered character of its governing body, its Council. Among its 40 members were the heads of the IASB, FASB, IFAC and International Organization of Securities Commissions (IOSCO), the CEOs of the 'Big Four', the heads of the major British professional accountancy bodies, and the CFOs of major multi-internationals, such as Nestlé, Tata and HSBC. The Council was dominated by the accountancy profession, preparers and regulators, who made up more than half its members. They outnumbered by far the few representatives of organizations that promoted social and environmental accounting (not an unexpected situation, obviously). The strong representation of conventional accountants sent an ambiguous message: either they were genuinely interested in reforming financial reporting or they were determined to control a new initiative that threatened their established position (this author has not any kind of conspiratory approach, at least I hope so!). Over time it has become crystal-clear which interpretation is correct (and the author keeps on not promoting any kind of conspiracy theory, definitely).

At the time of its formation, the IIRC's stated objective was to develop an internationally accepted integrated reporting framework by 2014 to create the foundations for a new reporting model to enable organizations to provide concise communications of how they create value over time. After a consultation process, the IIRC published the first version of its 'International Integrated Reporting <IR> Framework' (<IR> Framework) in December 2013.

One of its aims was to address this disconnect for many readers of sustainability reports. Over the following years it developed guidance for what it referred to as "connected reporting" where organizations were expected to draw report readers' attention to the main connections between those social, environmental and economic actions and outcomes that were material 
for the reporting organization. For in-depth cases studies from Aviva, BT, the Environment Agency, EDF Energy, HSBC, Novo Nordisk, Sainsbury's and West Sussex County Council for sustainability in practice see this reference: (Hopwood, Unerman \& Fries, 2010). Among the pioneering reporting organizations innovating in the area of integrated (rather than connected) reporting was the Danish pharmaceutical company Novo Nordisk.

Novo Nordisk has been publishing an integrated annual report since 2004 to reflect the company's Triple Bottom Line business principle. The company's Triple Bottom Line (concept coined by John Elkington, the founder of the British consultancy called SustainAbility, in 1994) ensures that decision-making balances profitability with longer-term societal interests. Novo Nordisk's 2011 Annual Report was named the Best Integrated Report at the Corporate Register Reporting Awards in London on 29 April. The award was given to the company that best combines non-financial aspects into their annual report, integrating the financial and nonfinancial aspects throughout. This is the fifth time that Novo Nordisk has won the award.

At the outset, one of the main distinguishing features of IR was its aim to provide a concise report (in a relatively few pages) that would indicate an organization's most material social, environmental and economic actions, outcomes, risks and opportunities in a manner that reflected the integrated nature of these factors for the organization. The intention was to use electronic forms of reporting to allow users of integrated reports to drill down to more detailed reports and other information on those elements reported in the integrated report in which they were most interested.

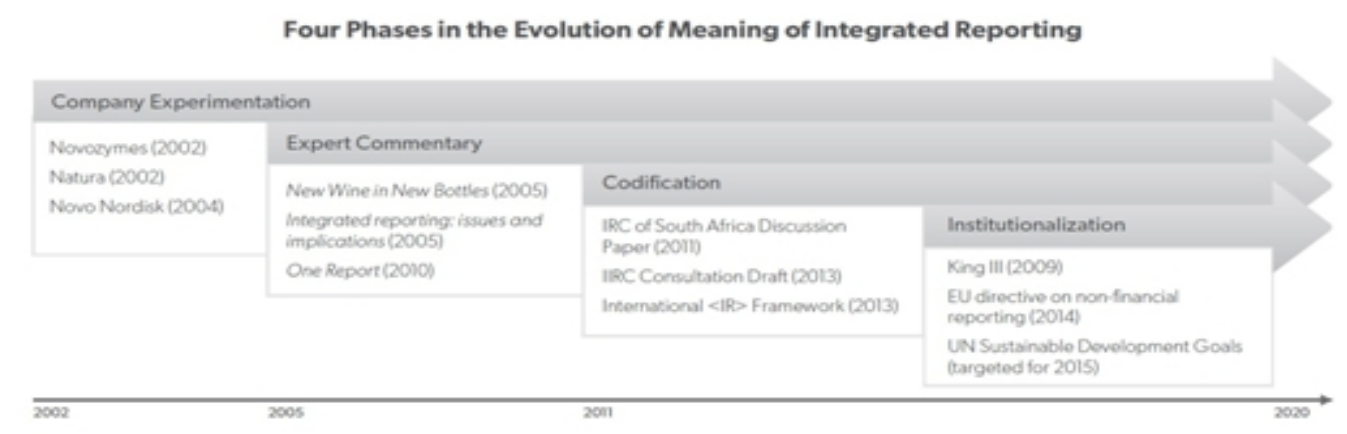

Figure 1. From Eccles and Krzus (2014)

Subsequent developments in the IIRC's thinking on IR shifted the emphasis from an organization's integrated report being a high level overview, towards the integrated report replacing other forms of corporate reporting. 
The IIRC therefore appear to have recognized that existing corporate reporting rules require fuller and more comprehensive financial disclosure requirements than would be possible if a relatively short integrated report were to replace (and broaden) existing financial reporting requirements.

One year ago had been signed a Memorandum of understanding between the IIRC and the Sustainability Accounting Standards Board emphasises that tearing down internal barriers and lessening duplication can bring greater cohesion and efficiency to the accounting and reporting process. This, according to these two international bodies, can help stakeholders elicit from organisations material information about their strategy, governance, performance and prospects in a clear, concise and comparable format. The Memorandum is available here: http://www.theiirc.org/wp-content/uploads/2014/01/MoU-IIRC-SASB-Final.pdf

\section{The fundamental concepts of IIRC}

The IIRC sees (IR) as an organization's value creation story. It explains how the organization will thrive in the short, medium and long term. It requires thinking beyond financial profit, thinking much more broadly about what creates value and what presents risk to value creation.

It is much more than bringing together financial and sustainability reporting - and also much less than that. It does not replace either financial or sustainability reporting - both need to be in place for IR.

IR requires a fundamentally different way of thinking about what makes an organization successful. It makes visible the organization's reliance on a much broader set of capitals than financial capital.

Although the implication is somewhat indirect and subtle, it is clear that the intent here is to define value in a way that does not place the providers of capital above all other interests in defining or creating value. That is, the notion of value espoused in the draft framework presents a direct challenge to the shareholder-driven model of capitalism that has dominated financial markets and corporate behavior during the past few decades.

Are we reaching a time when business value is really being redefined? "Value" has long been a favourite buzzword by business leaders and governments. Although widely-used, it can be troublesome because the interpretation of "value" is subjective. When we talk about "business" or "corporate" value, typically we are talking about financial performance. But do we really mean: cash flow; shareholder return; or valuations. Or all of the above? 
I believe there is growing opinion that this purely financial dimension of corporate value is becoming too narrow, and that we need a holistic view that acknowledges the broader value a business creates (or reduces) for both society and its shareholders.

To ensure long-term survival, business leaders will increasingly need to measure, manage and communicate the value they create for both society and shareholders. They will need to take decisions on the basis of both corporate and societal value creation, with a full appreciation of how the latter affects the former. In the next link a consideration of this approach authored by Barend van Bergen (Global Head of Sustainability Advisory in the Netherlands): https://agenda.weforum.org/2015/01/how-should-companies-define-value/?

utm_content=buffer667f1\&utm_medium =social\&utm_source=twitter.com\&utm_campaign=buffer

The other is the dimension of time. The framework states in many places and in many ways that the appropriate perspective includes the short, medium, and long term. This has the consequence of disfavoring strategies that emphasize short-term benefits at the cost of creating long-term risks, liabilities, or adverse outcomes, as well as of discounting the financial implications of such outcomes

THE INTERNATIONAL <IR> FRAMEWORK identifies three fundamental concepts: the value creation process; the capitals; and value creation for the organization and others. These three concepts are interrelated in that you can't apply one in isolation of the others. Simply put, the capitals are inputs to the organization's value creation process which creates value for the organization and its stakeholders.

The IIRC's Capitals Background Paper for <IR> (IIRC, 2013b) considers 'value' in the context of the six capitals. It recognises that organizations depend on all the capitals, not just financial capital, for their success and that some impacts on the capitals can only be reported on in narrative terms. It explicitly acknowledges that in their quest to create value overall, organizations might destruct or deplete the stock of one or more capitals in the process. That is, the notion of value espoused in the framework presents a direct challenge to the shareholder-driven model of capitalism that has dominated financial markets and corporate behavior during the past few decades.

The fundamental point is that IIRC accepts that the IR should cover the impact of the capitals on the firm, but ignores the firm's impact on these capitals, except to the extent that this impact rebounds on the firm -for example, within the people killed by the firm's release of poisonous gases include the firm's employee. The above analysis makes it abundantly clear that the IIRC requires a firm to report on the effect on its activities on stakeholders, on society and on the environment only to the extent that there is a material impact on its own operations. 
In the framework, the conventional reliance on financial capital as the sole or primary store of value or indicator of value creation (e.g., the change in the present value of discounted cash flows over time) has been broadened substantially. The six capitals are the next ones:

- Financial capital

- Manufactured capital

- Intellectual capital

- Human capital

- Social and relationship capital

- Natural capital

Rather, the capitals (which have been identified following extensive consultation and research) are intended to broaden thinking about the organization's long-term value creation process and ensure that an organization does not overlook a capital. This has the consequence of disfavoring strategies that emphasize short-term benefits at the cost of creating long-term risks, liabilities, or adverse outcomes, as well as of discounting the financial implications of such outcomes. In order to report performance on material Environmental, Social and Governance (ESG) issues, organizations should prepare a sustainability report (or provide sustainability disclosures online).

\subsection{Value creation}

The meaning attributed to 'value' and value to whom is critical in shifting the extent to which business, society and the environment co-exist in a mutually beneficial way. Is creating value about increasing shareholder wealth, improving the quality of lives of communities, enhancing our natural environment or all of these?

These tensions are to some extent drawn out in the IIRC's Value Creation Background Paper (IIRC, 2013c) prepared by Ernst \& Young (EY) with guidance from a multi-stakeholder expert steering committee. The International <IR> Framework acknowledges both value created for stakeholders and value created for the organization itself (see para. 2.4). The latter results in financial returns to providers of capital. An organization's external context, relationships, business activities and outputs all have an impact on value creation.

The value an organization creates (or depletes) for others can have an impact on long-term value creation for the organization and its providers of capital (see para. 2.5).

A business-society relationship characterised by trust and mutual advantage is critical to the long-term success of companies. The extent to which any individual organization transforms 
itself and contributes to transforming this relationship will depend on how they articulate what value creation means to them and the way in which stakeholder concerns influence 'value'. Also important is the extent to which the senior executive and board shift towards longer-term thinking.

The IIRC's Value Creation Background Paper considers value from the perspective of the organization and specifically from the perspective of providers of financial capital.

This could be interpreted by some as meaning business as usual - if you can't measure it in monetary terms, it's not important. Hence it is in order for a firm not to report on the impact of its activities on natural capital (for example in polluting the environment), where this has no significant impact of its own long-term profitability. In general the firm is obliged to report on capitals that are inputs to its production process, since the firm's profitability will generally be affected by the condition of these capitals. But it will often be the case that a firm's activities have a negative impact on other capitals but have no significant impact on firm's long term profitability. In such a case, according to the Framework there is no requirement to report this negative impact. This conclusion is based on the interpretation of "value" as "value to investors", if the IIRC has adopted a wider concept of value such as "value to society" then it would have been necessary for the firm to report on its impact of its activities on all capitals, irrespective of the impact on its own profitability.

Accountants could do much more than they have to date been inclined to measure the impacts of corporate business models across all six capitals and of stakeholder actions. IR could play an important role in this. But telling accountants, who play an important role in corporate reporting, that they should only include impacts if their financial value can be measured is unlikely to encourage lateral thinking. It comes down to how your organization defines value.

This assumes that companies

- have a desire to be accountable and

- have the know-how to report in this way.

It also points to the need for external assurance if reports are to be credible.

\subsection{The guiding principles}

The International <IR > Framework includes the following guiding principles:

- Strategic focus and future orientation

- Connectivity of information

- Stakeholder relationships 
- Materiality

- Conciseness

- Reliability and completeness

- Consistency and comparability

The Framework acknowledges that there are tensions between guiding principles (the obvious area for tension being between conciseness and completeness) and calls for judgement to be used in applying them. That is exactly why they are 'principles' - they are there to guide and to be applied with judgement.

In fulfilling the requirement that organizations provide insight into their 'strategic focus and future orientation' it is important to demonstrate that the strategy set out in the report is achievable. This can be done by describing how the past has led to the current strategic focus and highlighting key financial and non-financial performance indicators that demonstrate that strategy has been achieved in the past.

\subsection{Applying IIRC and fixing gaps in your integrated thinking}

Developing integrated thinking is a bit of an iterative process. You won't get it right first time and once you start reporting you will identify gaps in your thinking. And it is not until you report that some gaps will be noticed. Fixing the gaps (which you should expect to do only temporarily because it is a continual challenge) requires understanding why they occur. Likely reasons include:

- A belief that anything of value to business has to be measureable in monetary terms. This can be hard to shake and the education and training of accountants tends not to challenge it. The good news is that research shows that younger people are seeking to work for organizations that are socially responsible, practise sustainability and are ethical. Those whose responsibilities involve creating value through non-financial means need to clearly articulate the value created to the organization and its stakeholders by their initiatives.

- Organisational structures which predate the complexity of the contemporary, complex and globalised business environment. There are still an abundance of organizations with thriving silos. If organizations are to thrive they need to get better at working across these silos by developing formal and informal communication channels and networks.

- The predominance of leaders who lack a 'moral compass' and hence authenticity. If this applies you may well have bigger issues to deal with than fixing gaps in integrated thinking. 


\subsection{What your report needs to include - The content elements}

The content elements guide what goes in your integrated report. They are:

- Organizational overview \& external environment

- Governance

- Business model

- Risks and opportunities

- Strategy and resource allocation

- Performance

- Outlook

- Basis of presentation

- General reporting guidance

To comply with the International IR Framework an integrated report should answer the following questions:

- "What does the organization do and what are the circumstances under which it operates?" (para. 4.4)

- "How does the organization's governance structure support its ability to create value in the short, medium and long term?" (para. 4.8)

- "What is the organization's business model?" (para. 4.10)

- "What are the specific risks and opportunities that affect the organization's ability to create value over the short, medium and long term, and how is the organization dealing with them?" (para. 4.23)

- "Where does the organization want to go and how does it intend to get there?" (para. 4.27)

- "To what extent has the organization achieved its strategic objectives for the period and what are its outcomes in terms of effects on the capitals?" (para. 4.30)

- "What challenges and uncertainties is the organization likely to encounter in pursuing its strategy, and what are the potential implications for its business model and future performance?" (para. 4.34)

- "How does the organization determine what matters to include in the integrated report, and how are such matters quantified or evaluated?" (para. 4.40) 
This should be relatively straightforward if you've done the integrated thinking work outlined in previous earlier chapters.

\subsection{Achieving connectivity of information}

Connectivity is something to keep a check on throughout the reporting process. The following bits of information need to connect:

- Content sections of an integrated report

- Relationship between past performance and future strategy

- Six capitals

- Integrated report and other corporate reports

To do this well, you need a culture of collaboration and communication processes which cross functional silos. The term "silo" was created to indicate a similarity between grain silos that separate one type of grain from another and the segregated parts of a company. In a company suffering from silo syndrome, each business unit or function interacts primarily within its own "silo" rather than with other groups across the company.

The term "functional silo syndrome" was coined in 1988 by Phil S. Ensor who worked in organizational development and employee relations for Goodyear Tire and Rubber Company, Eaton Corporation, and as a consultant. "Silo" and "stovepipe" are now used interchangeably and applied broadly.

The problems of "silos" show up in duplication of cost and effort, working at cross purposes, lack of synergy, little knowledge transfer or economies of scale. The largest problem, however, is a lack of alignment with the overall company strategy. These can be developed with time. It may require fixing the reasons why gaps in information occur:

- Belief that anything of value to business has to be measureable in monetary terms

- Organisational structures that predate the complexity of the contemporary, complex and globalised business environment

- Territorial and hierarchical (i.e. 'masculine') leadership styles

- The predominance of leaders who lack a 'moral compass' and hence authenticity

\section{Benefits of preparing an integrated report}

The process of developing an IR brings real benefits. It highlights gaps in thinking, systems and processes. It involves thinking long term and collaboration across functions - or 'breaking 
down silos' that I have highlighted in the previous point. It ensures that material sustainability issues and risks get board-level attention.

Most innovations come from getting people from different functions and backgrounds together. The integrated thinking needed to produce an integrated report requires working together in setting your strategy and thinking about your business model.

The top two benefits of IR are perhaps in:

- Transforming decision-making processes in a way which aligns benefits to business, society and the environment. (A win-win all round - if it is done well.)

- Better risk identification and mitigation. (A win for the company, its directors and the stakeholders it impacts.)

Realising these benefits is utterly dependent on a long-term time horizon and incentives are needed to facilitate this. The decision to change the nature of an organization's reporting involves changes in what information is collected, how it is presented and ultimately, what aspects of an organization's activities, processes and outcomes are made visible.

In summary, IR brings benefits through:

- emphasising the need for long-term planning

- encouraging thinking about the business model in much broader terms than flows of money

- focusing on creating value across all six capitals

- developing a culture of collaboration, breaking down silos

- getting senior execs and the board involved in considering these issues.

An inappropriate focus on the short term at the (possible) expense of long-term corporate and societal health is a major concern to many investors and other stakeholders. It is also worthy of note that short-term thinking can severely constrain an organization's ability to make appropriate investments in improving ESG performance and sustainability more generally.

\section{Lack of compulsion}

The IIRC is consistently very deferential to the company's management, in giving it very wide discretion in what is to be reported. The obligations of preparers are set out in the following very broad terms:

"Any communication claiming to be an integrated report and referencing the Framework should apply all the requirements identified in bold italic type unless: 
- The unavailability of reliable information or specific legal prohibitions results in an inability to disclose material information.

- Disclosure of material information would cause significant competitive harm." (IIRC, 2013a, para. 1.17)

Only 19 of the Framework's 168 paragraphs are set in bold italic type (which renders them binding on preparers) and all of these are formulated in very broad terms that impose no specific reporting obligations. Furthermore, even these obligations are only conditional mandatory for preparers and they may disregard them on any of three grounds:

- Legal prohibition

- Unavailability of data

- Competitive harm

The IIRC does not require firms to report on any specific KPIs (Key Performance Indicators). This approach is at odds with that taken by the GRI, one of the IIRC's two funding organizations. In its guidelines, the GRI specifies no less than 34 environment performance indicators and 48 social performance indicators; for example the guideline EN15 requires companies to "report gross direct CHG (greenhouse gas) emissions in metric tonnes of $\mathrm{CO} 2$ equivalent, independent of any GHC trades, such as purchases, sales, or transfers of offsets or allowances" (GRI, 2013, pp. 107-109), as well as six additional items of information relating to greenhouse gas emissions. If a company does not report this information (or provide a valid reason for not disclosing), it is forbidden to state that this report has been drawn up in accordance with the GRI's guidelines. Instead of this, the IIRC places no such obligation on the company's management.

\section{A proposal of future points to include in the research agenda}

The IIRC framework reflects very extensive thought and work by a variety of people familiar with the limitations of conventional public reporting of corporate operating and financial information. Although the framework is written in an accessible and easily understood fashion and is principles-based rather than detailed and prescriptive, it contains many features that are profound and potentially far-reaching.

To use a crude analogy, talking about integrated reporting is somewhat akin to talking about world peace - almost everyone thinks it's a desirable goal, and most of us want to believe it's achievable, but we realise that it's not easy to deliver. Furthermore, some of us are starting to wonder if it will ever truly take hold. Like many good ideas, integrated reporting comes with a range of promises and associated expectations - transformative in how organisations account 
for performance; focused on outcomes rather than outputs; holistic in its consideration of businesses as potential creators of shared value; providing recognition of how financial, ethical, social and environmental factors are intertwined in creating this value; delivered to an audience that is more than ready to move beyond narrowly-focussed, short-term, backwardlooking accounting.

Many or most of the changes that are explicitly required or implied by the framework are either needed or are desired by a wide range of external stakeholders. Whether, and to what extent, corporate leaders will find the framework suitable and, indeed, workable, is less clear. Complying with the terms of the framework would pose some challenges. Embracing and taking action on many of its implied goals would require major organizational change for most companies, and not a small amount of investment. It is my sense, however, that organizations that made this investment would reap many benefits, including substantially improved stakeholder relationships, reputation, and brand value, as well as new insights into how they can best use their resources to create financial and other value, improve their responsiveness and resilience, and compete successfully during a time of substantial volatility and technological change.

Creating and Preserving Value is a key theme in IR. While one might argue that value is determined by considering all stakeholders, the focus on value rather than impacts moves IR further away from the accountability focus that has been, in my view, a pivotal factor in the development of sustainability reporting. I think this positioning -value creation versus accountability - is one of the basic differences in perception between financial reporting and sustainability reporting. The Framework expects to include a definition of value, just to make it clear for everyone -and the implication is that by using the capitals system, the definition of value will be broadened to include value for all stakeholders rather than purely financial value for shareholders. But what I am not sure about is whether there is a loophole that assumes you can create value without being accountable? If IR focuses on value creation, who focuses on accountability?

The IIRC calls resources and relationships "capitals" of which there are six: financial, manufactured, human, intellectual, natural and social. Why call them capitals when they are actually resources? Almost any definition of capital you look at makes the connection between capital and creating money. If all that the new approach to IR is doing is changing the words we use to refer to creating money, I am not sure we haven't lost the plot.

"There is still much confusion about the distinction between sustainability reporting and integrated reporting. From an investors' perspective it is absolutely critical that integrated reporting is positioned firmly within the realm of value creation and in a manner that speaks to the boards and financial (reporting) departments of companies". (quoted from Claudia Kruse, 
Head of Governance \& Sustainability, Asset Management at APG All Pensions Group written in the Integrated Report Blog, available here: http://integratedreporting.org/news/rio20-the-investorsperspective/)

How integrated is that? I understand the need for investors to seek ESG information. I understand that the financial community is looking for another way to safeguard their cash. If all we are doing is moving from Financial Reporting to Value Reporting by adding in a few more ESG context-related content areas, then there is no new distinction. There will be Integrated Reporting and Sustainability Reporting. Just like now. Annual Reporting and Sustainability Reporting. If IR becomes the primary reporting vehicle, we may well see reduced levels of social and environmental reporting with non-shareholder groups further marginalized than they already are. As such, IR (in effect, if not intention) seems more likely to reinforce rather than transform (unsustainable) "status quo" pathways.

The way IR is now conceptualised in 2015 , with a strategic focus on future actions and plans focusing specifically value creation, stands in stark contrast with the original 2010 foci on stakeholders (other than shareholders) and accountability for the impacts of corporate activities. This shift means that the target audience for the IR is now substantively different from that of sustainability reports.

While sustainability reporting aims at providing social, environmental and economic information to a wide range of stakeholders, IR now seeks to present information related to broad risk evaluation and potential future value growth thus appealing to capital providers and potential investors.

Therefore, whereas the GRI (2013) G4 guidelines emphasise the need to identify stakeholders and through their concerns to identify organizations' social and environmental impacts, the IIRC'S IR framework focus is on "shareholder value".

This contrast naturally leads to several questions that would benefit from in-depth impartial academic study, especially in research about the IIRC's version of IR:

- Who will assist organizations in identifying concerns related to the social and environmental capitals (according to the IIRC, human, social and relationship, and natural capitals), if not the stakeholders who represent these capitals?

- Given this different method of identifying concerns, how will the disclosures around social and environmental (or human, social and relationship, and natural) capitals differ between (IIRC-type) integrated reports and (GRI-type) sustainability reports?

- Will more CEOs and CFOs, some for the first time, consider the direct and indirect negative influences their operations have on social and environmental (or human, social and relationship, and natural) capitals? 
- To what extent will specific mechanisms be created for the purpose of weighing up these matters, or will the IIRC's privileging of shareholder interests entrench the neglect of social and environmental capitals, being for the most part externalities to the organization? The possible broadening of the internal processes mentioned above will potentially influence risk management and audit. The concept of materiality is central to both risk and audit (and this interrelation both in sustainability and financial fields). In addition, the future orientation of the IIRC's integrated report implies serious consequences for firm risk and external auditors. Again, several questions are yet to be answered and represent fertile ground for future academic research.

- How will organizations, especially business organizations, deal with the risk inherent in making predictions about the future, as required by IIRC-type IR?

- How will the differences in institutional rules and structures, as well as corporate culture, in different countries influence the practice of IR, with special reference to the differential risk of litigation?

- Will IR prompt auditors to find innovative ways to deal with the issue of being unable/unwilling to express an opinion on future-oriented information?

- How will the renewed focus on risk prompted by IR change firms' internal risk assessment processes?

Another implication related to the implementation of IR relates to the need to incorporate compliance methodologies into performance and assurance frameworks. Assurance service providers may have to combine IR with existing regulatory requirements on annual reports.

However, there may also be a need for regulatory bodies to change their auditing standards. This will represent another fascinating area for research, aimed at answering questions like:

- What mechanisms are most effective in prompting assurance service standard setters to change their standards to accommodate the requirements of IR?

- Will financial audit standards and sustainability assurance standards converge, and what would prompt such convergence?

- Which stakeholders are most influential in affecting the direction of IR audit and assurance standard setting?

Of course, these musings on audit and assurance standard setting lead to questions around IR standard setting, such as:

- What role do power relationships among stakeholders play in IR standard setting?

- Which stakeholders are most influential in affecting the direction of IR standard setting? 
- How did the IIRC establish international legitimacy so quickly, compared to, for example, the International Accounting Standards Board?

- Will there be attempts at convergence between bodies promoting IR and bodies promoting financial reporting standards such as the IIRC and the International Accounting Standards Board?

- What is the role of accountants and professional accounting bodies in creating new standards and ensuring additional work for and job reservation for members of their organizations in the context of development of IR?

Also, we are interested in the following additional researchable questions:

- How and to what extent are IR processes truly integrated and are these processes truly embedded in organizations' management control systems?

- How and to what extent does IR influence the consideration of the material impacts of the business across the entire value chain?

- How do organizations go about producing a concise integrated report, whilst covering all the capitals and all the perspectives suggested by the IIRC?

- Given that an IIRC integrated report has a particular focus, how/where is it generally published by organizations and what is its relationship to the statutory annual report?

- Is the decision to disclose an integrated report value relevant, in other words do the financial markets react or reflect a value premium in any way, or a discount in the case of not disclosing it?

- How can a good integrated report be distinguished from others, in other words are there particular metrics that capture the characteristics of a good integrated report? One initiative in this field is The CR Reporting Awards (CRRA), global online CR reporting awards. Launched in 2007 to identify and acknowledge the best in corporate non-financial reporting, the CRRA are managed by CorporateRegister.com -the CR resources website and provider of the world's largest online directory of $C R \&$ Sustainability Reports. One of the nine CRRA awards is the "Best Integrated Report". (Novo Nordisk A/S had been the winner in the last three editions of the "Best Integrated Report" category). More information available here: http://www.corporateregister.com/crra/help/crraabout.html

- Which metrics best align with market reactions or market reflections of value?

- What can we learn from firms' integrated reports about the implementation of the IIRC guidelines and the relative importance firms ascribe to conflicting requirements? 
The extent of the above questions further indicates the need for quality researchers to address a number of pressing challenges posed by the rapid development of IR policies and practices.

For the moment there is one resource provided by the Secretariat of the IIRC. It is a database available online with examples that have been be selected from publicly available reports and that can be used by organizations that are developing, or planning to develop, an Integrated Report. The database does not provide definitive guidance, and examples have not been selected on the basis of criteria designed to rate the relative merits of various reports, as would be the case in an awards program. Rather, the examples have been selected simply to provide a range of emerging reporting practices that organizations may choose to adopt or modify to suit their individual circumstances. The database has been structured around the Guiding Principles, Fundamental Concepts and Content Elements presented in the IIRC's International <IR> Framework. The project partners intend to update the database in accordance with revisions to the Guiding Principles, Fundamental Concepts and Content Elements, if any, as the International Integrated Reporting Framework is further developed.

\section{References}

CHENG, M.; GREEN, W.; CONRADIE, P.; KONISHI, N.; ROMI, A. (2014). The International Integrated Reporting Framework: Key Issues and Future Research Opportunities. Journal of International Financial Management \& Accounting, 25(1): 90-119. Available online at: http://onlinelibrary.wiley.com/doi/10.1111/jifm.12015/full http://dx.doi.org/10.1111/jifm.12015

DE VILLIERS, C.; RINALDI, L.; UNERMAN, J. (2014). Integrated Reporting: Insights, gaps and an agenda for future research. Accounting, Auditing \& Accountability Journal, 27(7): 1042-1067. http://dx.doi.org/10.1108/AAAJ-06-2014-1736

ECCLES, R.G.; KRZUS, M.P. (2014). The Integrated Reporting Movement: Meaning, Momentum, Motives, and Materiality. New Jersey: John Wiley \& Sons.

GRI (2013). G4 Sustainability Reporting Guidelines. Implementation Manual. Available online at: https://www.globalreporting.org/resourcelibrary/GRIG4-Part2-Implementation-Manual.pdf

HOPWOOD, A.G.; UNERMAN, J.; FRIES, J. (2010). Accounting for Sustainability. Practical Insights. London: Earthscan Publications.

IIRC (2013a). International $<I R>$ Framework. Available online at: http://www.theiirc.org/international-ir-framework/

IIRC (2013b). Capitals Background Paper for $<I R>$. Available online at: http://www.theiirc.org/wpcontent/uploads/2013/03/IR-Background-Paper-Capitals.pdf 
IIRC (2013c). Value Creation Background Paper for <IR>. Available online at: http://www.theiirc.org/wp-content/uploads/2013/08/Background-Paper-Value-Creation.pdf

KING REPORT ON GOVERNANCE FOR SOUTH AFRICA (King III) (IRCSA, 2011). Available online at: https://jutalaw.co.za/uploads/King_III_Report/\#p=1

Intangible Capital, 2016 (www.intangiblecapital.org)

Article's contents are provided on an Attribution-Non Commercial 3.0 Creative commons license. Readers are allowed to copy, distribute and communicate article's contents, provided the author's and Intangible Capital's names are included. It must not be used for commercial purposes. To see the complete license contents, please visit http://creativecommons.org/licenses/by-nc/3.0/. 